\title{
Participar soberanamente do mundo que se globaliza
}

\author{
José Marques de Melo
}

\section{SciELO Books / SciELO Livros / SciELO Libros}

MELO, JM. Cidadania glocal, identidade nordestina: ética da comunicação na era da internet [online]. Campina Grande: EDUEPB; Latus, 2011. 108 p. ISBN 978-85-63984-07-4. Available from SciELO Books $<\underline{\text { http: } / / \text { books.scielo.org }>\text {. }}$

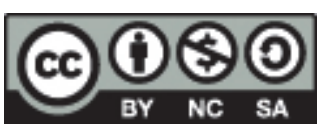

All the contents of this work, except where otherwise noted, is licensed under a Creative Commons Attribution-Non Commercial-ShareAlike 3.0 Unported.

Todo o conteúdo deste trabalho, exceto quando houver ressalva, é publicado sob a licença Creative Commons Atribuição Uso Não Comercial - Partilha nos Mesmos Termos 3.0 Não adaptada.

Todo el contenido de esta obra, excepto donde se indique lo contrario, está bajo licencia de la licencia Creative Commons Reconocimento-NoComercial-CompartirIgual 3.0 Unported. 


\section{Participar soberanamente do mundo que se globaliza ${ }^{5}$}

Há 50 anos, cheguei a Pernambuco com

uma ideia fixa na cabeça. Ser jornalista pleno e não um mero praticante do ofício, como eu me considerava naquela época. Tendo começado a improvisar reportagens e a exercitar artigos, em minha terra natal - Alagoas -, depois de um ano, eu sabia fazer o trivial na redação do jornal diário em que exercia a profissão. Mas me considerava jornalista pela metade, porque aprendera o fazer, mas não detinha o saber. Ambicionando muito mais, eu desejava conhecer os fundamentos do jornalismo, sua natureza, suas implicações socioculturais.

5 Discurso pronunciado no dia 22 de abril de 2010, durante a cerimônia de outorga do título de Doutor Honoris Causa pela Universidade Católica de Pernambuco. 
Pelos rumores que circulavam em nosso meio, eu acompanhava as tentativas de fundação do ensino de jornalismo nas capitais das províncias vizinhas, inclusive aqui no Recife. Mas fiquei decepcionado, ao telefonar para o colégio Nóbrega, onde funcionava a faculdade de filosofia mantida pelos padres jesuítas, concluindo que o curso superior de jornalismo era ainda um projeto em tramitação.

Buscando uma opção plausível para atingir a meta fixada, terminei me inscrevendo no vestibular da faculdade de direito, pela qual transitavam os principais intelectuais da região e onde eu poderia adquirir uma visão holística da superestrutura da sociedade.

Fui bem sucedido, classificado em segundo lugar no exame, apesar de não ter feito o curso clássico no segundo grau. Naquele tempo, o resultado do vestibular era notícia. Mas eu me acotovelei no saguão da Casa de Tobias Barreto, como era chamado o belo edifício onde funciona a Faculdade de Direito da então Universidade do Recife, para ver a lista dos aprovados afixada no "quadro de avisos". Só depois de certificar-me que meu nome constava da lista dos aprovados, li a notícia publicada no Diário de Pernambuco, contendo referências aos primeiros colocados, numa reportagem de quase metade de página. 
Confesso, porém, que outra informação me pareceu mais atraente, naquela seção do "mais antigo jornal diário em circulação na América Latina". Tratava-se de uma notinha de pé de página, ignorada pelos meus colegas eufóricos, comemorando o sucesso obtido naquele rito de passagem. A matéria referia-se à abertura de inscrições para o vestibular no recémfundado curso de Jornalismo da Universidade Católica de Pernambuco. Não perdi tempo, escapulindo imediatamente do pátio interno da veneranda faculdade. Desembestei degraus abaixo, caminhando velozmente pela rua do Príncipe, até chegar, esbaforido, a uma das casinhas anexas à Residência dos Jesuítas, onde funcionava a Secretaria.

Ao adentrar o recinto, fui atendido por Dadá, a toda-poderosa Secretária-Geral desta universidade, que me indicou, dedo em riste: Jornalismo é com o professor Luiz Beltrão. Esperei no balcão o atendimento das pessoas que me precederam, todas elas exibindo o recorte de jornal com a notícia sobre o novo curso. Luiz Beltrão me atendeu com objetividade, dando as informações essenciais sobre a prova e me animando a concorrer a uma das vagas, apesar de originário do curso científico. Vi ligeiramente o programa, constatando minhas carências cognitivas. Procurei supri-las, lendo, em poucos dias, obras disponíveis para 
empréstimo na rede de bibliotecas públicas do Estado de Pernambuco.

Aprovado nesse novo vestibular, tive o privilégio de integrar a primeira turma do Curso de Jornalismo, começando uma bela aventura intelectual que culminou com a minha formatura em 1964, meu ingresso no seu quadro de pesquisadores em 1965, a promoção ao corpo docente em 1966 e a manutenção de um vínculo permanente com esta universidade. Aqui retornei, por exemplo, em 1970, para o lançamento nacional do meu livro Comunicação Social: Teoria e Pesquisa e, em 2001, para comemorar o cinquentenário desta institui60 ção, que me prestou simpática homenagem com a publicação da minha biografia, incluída na série "Grandes Nomes da Comunicação", publicada pelo Centro de Estudos da Imprensa e da Cidadania. Mas seu verdadeiro ápice, eu o estou vivenciando, aqui e agora, no momento em que esta Universidade me confere o título de Doutor Honoris Causa, na abertura do XIII Encontro do Fórum Nacional dos Professores de Jornalismo.

Sinto-me naturalmente lisonjeado com a iniciativa tomada pela professora Aline Grego, em conjunto com os docentes do Departamento de Comunicação, mas fico embaraçado ao proferir o tradicional discurso de agradecimento. Espera-se, em solenidades desta natureza, que 
o homenageado faça uma alocução motivadora, em certo sentido otimista, concitando as novas gerações para darem continuidade ao trabalho iniciado pelos nossos pioneiros e aperfeiçoado pelos seus continuadores.

Pensei muito sobre o que diria nesta ocasião. Procurei discernir o que há de novo no panorama da nossa sociedade. Mas fiquei triste ao constatar que tudo permanece como dantes no quartel de Abrantes.

O revertério institucional decorrente da decisão do STF, declarando inconstitucional a lei de imprensa e abolindo, na sequência, a obrigatoriedade do diploma para o exercício da nossa profissão, praticamente nos reconduz aos cenários que Luiz Beltrão vislumbrava no início dos anos 60, lutando pela formação universitária dos jornalistas.

Mais grave ainda é a postura adotada pelo nosso Judiciário, arvorando-se como árbitro da liberdade de imprensa e amordaçando jornais e jornalistas, em todo o território nacional. Apesar da vigência do preceito constitucional que inibe o legislativo e coíbe o executivo para censurar a mídia, testemunhamos a profusão de sentenças judiciais que interferem no processo informativo, criando um ambiente emoldurado por grande perplexidade.

Por isso mesmo, cheguei à conclusão de que, apesar dos incomensuráveis avanços 
tecnológicos alcançados nos últimos anos, alargando os horizontes jornalísticos e ampliando nossas fronteiras cognitivas, a conjuntura vivenciada atualmente preserva muito dos elementos que faziam parte do quadro de referências com que me defrontara em 1964, quando me formei nesta universidade e fui escolhido como orador da minha turma de jornalistas diplomados.

Percebi, então, que a maldição de Sísifo constitui um estigma do qual nós, jornalistas, dificilmente nos desvencilhamos, não apenas na rotina produtiva, mas, sobretudo, no processo de construção da nossa identidade 62 profissional.

Diante dessa contingência, entendi que nada mais atual para dizer aqui, senão relembrar, ratificar e reafirmar as ideias-força que propus aos meus colegas de formatura no ato da nossa diplomação solene, no dia 13 de dezembro de 1964.

A mais importante de todas é a defesa da formação universitária dos jornalistas. Endossei essa tese, fundamentado no argumento de Walter Ramos Poyares, que durante meio século assessorou o conglomerado midiático mais conhecido do país, as Organizações Globo.

- "Estou convencido de que teremos uma imprensa tanto melhor quanto melhor 
formação dermos aos jornalistas. (...) Nada contribuirá mais decisivamente para que a imprensa se torne responsável do que o levantamento do nível de formação dos jornalistas, \{dando-lhes\} um sentido ético e uma consciência profissional que suprimam os ainda vigentes abusos da liberdade, a exploração do sensacionalismo malsão, o desrespeito aos direitos da pessoa humana".

Contrapunha-se, então, a essa perspectiva do jornalista diplomado, aquela imagem romântica do jornalista que só adquiria tarimba na prática, típica do "jornalismo boêmio" do início do século passado, que agia como caudatário dos acontecimentos.

Sepultando essa visão inercial ou eventualmente reativa, o jovem Luiz Beltrão, sindicalista que exercera a vice-presidência da Federação Nacional dos Jornalistas e autor do clássico Iniciação à Filosofia do Jornalismo (Rio, Agir, 1960), fortalecia o perfil do jornalista responsável, sujeito do processo em que estava emaranhado intelectualmente.

"Como expressiva parcela do povo o jornalista não deve permanecer passivo diante dos problemas, limitando-se a expô-los ou criticálos leviana e inconseqüentemente. A sua posição é de um efetivo participante da elaboração do Direito, da luta pelo desenvolvimento constante das condições econômicas e sociais 
das comunidades a cujo serviço se encontra, de contribuinte na obra de entrosamento dos cidadãos na vida política da nação, de colaborador permanente na tarefa da paz e do entendimento entre todos os povos do mundo."

Ao lutar pelo desenvolvimento que dinamiza a melhoria das condições de vida na sociedade, compete ao jornalista discernir o que interessa soberanamente ao povo brasileiro, precavendo-se em relação às pressões do poder econômico, inclusive dos grupos exógenos, hoje rotulados como empresas multinacionais.

Permanecem válidas, a esse respeito, as 64 lições ponderadas, mas enérgicas e estratégicas do jornalista Celso Furtado, que se converteu em signo do desenvolvimento econômico regional.

"Devemos ter um estatuto legal que discipline a ação do capital estrangeiro, subordinando-o aos objetivos do nosso desenvolvimento econômico e da independência política. Deve o governo dispor, ainda, de meios para conhecer os recursos aplicados nos órgãos que orientam a opinião pública".

Está enunciado, portanto, o tripé que dá sustentáculo ao desenvolvimento do jornalismo e à formação de novos jornalistas capazes de participarem desse fascinante processo de construção da soberania nacional e de 
inserção vigorosa do nosso país no espaço de um mundo que se globaliza, mas não pode perder sua fisionomia multicultural.

Nesse sentido, vale a pena reproduzir literalmente a peroração que fiz aos meus colegas de turma de Jornalistas diplomados em 1964, amparado na advertência antológica de Rui Barbosa, cuja mensagem readquire vigência neste momento em que o nosso jornalismo patina numa crise profunda e enigmática, mas ao mesmo tempo estimulante e desafiadora.

"Sem que tais medidas sejam tomadas o nosso país assumirá perante a comunidade internacional aquele triste papel delineado por Rui Barbosa: Um país de imprensa degenerada ou degenerescente é um país cego e um país de idéias falsas, miasmado, um país, que, explorado na sua consciência, não poderá lutar com os vícios que exploram as instituições. Logo, a nossa posição na vida profissional deve ser exatamente a de vigilantes. Vigilantes para que as informações fornecidas ao público sejam verdadeiras e exatas, vigilantes para que elas sejam dotadas de honestidade e respeito à dignidade humana". (MARQUES DE MELO, José-1965 - Da responsabilidade social no Jornalismo, Recife, ICINFORMO 